\title{
Oralidade e as estratégias de progressão temática: práticas com o gênero seminário em una turma de $9^{\circ}$ ano
}

Orality and the strategies of thematic progression: practices with the genre seminar in a $9^{\text {th }}$ grade class

Evaldo Ribeiro de Andrade Universidade Estadual do Piauí - UEPI

Bárbara Olímpia Ramos Melo

Universidade Estadual do Piauí - UEPI

DOI: https://doi.org/10.5902/2176148538616

Resumo: O seminário é caracterizado principalmente pela atividade de expor e a sua progressão temática pode ser efetivada pelo uso de diferentes estratégias. Nesse sentido, o presente trabalho objetiva analisar as estratégias de progressão temática de seminários apresentados por alunos de uma turma de $9^{\circ}$ ano de uma escola pública de Teresina-PI. Metodologicamente, quanto aos objetivos, desenvolveu-se uma pesquisa exploratória e descritiva. Após a apresentação dos seminários, constatou-se que alguns grupos conseguiram operacionalizar mais estratégias que outros e, por isso, mantiveram, por mais tempo, a plateia atenta ao que era exposto.

Palavras-chave: Oralidade. Seminário. Estratégia de progressão temática. Ensino.

Abstract: The seminar is characterized mainly by the activity of exposing and its thematic progression can be effected by the use of different strategies. In this sense, the present work aims to analyze the strategies of thematic progression of seminars presented by students of a 9th grade class from a public school in Teresina-PI. Methodologically, regarding the purposes, an exploratory and descriptive research was developed. Following the presentation of the seminars, it was found that some groups were able to operationalise more strategies than others and, therefore, they caught the audience's attention to what was being exposed for more time.

Keywords: Orality. Seminar. Strategy of thematic progression. Teaching. 


\section{Evaldo Ribeiro}

Andrade

Bárbara

Olímpia

Ramos Melo

\section{Introdução}

Recentemente, a Base Nacional Comum Curricular - doravante BNCC (BRASIL, 2018) traz como um dos eixos fundamentadores para as aulas de Língua Portuguesa o ensino da oralidade. Os Parâmetros Curriculares Nacionais doravante PCN (BRASIL, 1998), ao considerar a modalidade oral como parte integrante do ensino de língua materna, já preconizavam o ensino de gêneros orais. Nesse sentido, os documentos norteadores do ensino de Língua Portuguesa, no Brasil, demostram a importância do trabalho com a linguagem oral tendo em vista a necessidade de formar usuários competentes da língua.

A diferença elementar entre esses documentos, relacionadas às praticas de oralidade, é que a BNCC prescreve os conhecimentos essenciais, as competências e habilidades linguísticas a serem desenvolvidas em cada etapa da Educação Básica. Dessa forma, ao assumir o papel de ensinar o aluno a utilizar a linguagem oral no planejamento e realização de atividades que serão úteis ao desenvolvimento das competências comunicativa e linguística dos discentes, a escola vale-se de diversos gêneros, tais como realização de entrevistas, debates, seminários, apresentações teatrais, discursos políticos, causos, entre outros.

Para o fim a que se destina este trabalho, optou-se por trabalhar com o gênero oral seminário. Tal gênero é caracterizado principalmente pela atividade de expor e, na sua configuração, a progressão temática pode ser efetivada pelo uso de diferentes estratégias que, por um lado, ajudam na contextualização do tema, chamando a atenção do auditório, e por outro, a topicalizá-lo.

Nesse sentido, o presente trabalho objetiva analisar as estratégias de progressão temática de seminários apresentados por uma turma de $9^{\circ}$ ano de uma escola pública de Teresina-PI. O problema investigado propôs-se a descrever quais estratégias de formulação textual são operacionalizadas pelos alunos durante a apresentação de um seminário. Trabalhou-se com a hipótese de que os discentes apresentam o seminário utilizando poucas estratégias que possibilitem a progressão textual.

Dentre outros autores, este artigo está fundamentado nas postulações teóricas de Bueno e Abreu (2010), Gonçalves (2009), Gomes-Santos (2012) e Dolz (2004). Metodologicamente, quanto aos objetivos, desenvolveu-se uma pesquisa exploratória e descritiva e o corpus de análise foi composto pela transcrição da apresentação de seis seminários em que se apresentam as estratégias de progressão temática propostas por Gomes-Santos (2012). 
Em razão de seus desdobramentos, esta pesquisa organiza-se em diferentes seções. Na primeira, é discutida a questão do ensino de gêneros orais. Na segunda, apresenta-se a definição de seminário e algumas de suas estratégias de progressão temática. Já na metodologia, é feita a caracterização da pesquisa; apresentam-se os sujeitos e os temas dos seminários. Ao final, é apresentada a seção referente à análise e à discussão dos dados e as considerações finais em que se discorre sobre a experiência vivenciada durante a realização dessa investigação.

Oralidade e as estratégias

\section{Para início de conversa: implicações sobre o ensino} de gêneros orais

de progressão

temática

A complexidade do processo de construção do texto em geral e do texto oral, em particular, inegavelmente envolve uma gama de atividades e estratégias. Nesse processo de construção, o falante visa à produção de sentidos, possibilitando a interação verbal.

De cunho social, essa interação está intimamente ligada à oralidade, uma vez que o texto falado apresenta uma sintaxe característica, sem, no entanto, deixar de lado a sintaxe geral da língua, e se configura num processo dinâmico com uma estruturação própria ditada pelas circunstâncias sociocognitivas de sua produção.

Nesse sentido, qualquer texto, escrito ou falado, é resultado de uma coprodução entre interlocutores, conforme destaca Koch (2015), sendo que no texto falado, pelo fato de os interlocutores já poderem estar copresentes, ocorre também uma interlocução ativa, refletindo um processo de coautoria entre os participantes da situação discursiva. Isso ocorre porque os recursos tecnológicos, a exemplo de canais midiáticos como o Youtube, as chamadas pelo Skype ou um stream de videojogo pelo Twitch, permitem a realização do texto oral através da copresença de seus interlocutores.

De certo modo, é preciso destacar as diferenças de grau de manifestação da produção ou coprodução discursiva, conforme o texto apresente um teor mais dialógico ou menos dialógico. Há textos orais em que a produção/coprodução verbal é bem ativa, como as conversas espontâneas, já em outros, a exemplo das elocuções formais (exposições acadêmicas, seminários) o teor é menos dialógico, com uma coprodução verbal menos ativa.

Por isso, o desconhecimento teórico-prático sobre os gêneros orais e consequentemente sobre as práticas de oralidade é compreendido quando se analisa a tradição escolar que, em ralação às práticas 


\section{Evaldo Ribeiro}

Andrade

Bárbara

Olímpia

Ramos Melo

de linguagem, "quase sempre recorre à escrita como objeto de ensino e, quando se trata de trabalhar com a linguagem oral, poucas ou quase inexistentes são as orientações e proposições", conforme afirma Costa-Hübes e Swiderski (2015, p. 140). As autoras também enfatizam que existem poucas publicações direcionadas aos gêneros orais e que essa forma de materialização da linguagem, como instrumento de ensino e aprendizagem, ainda não recebe a devida atenção na sala de aula.

Mesmo os PCN e a BNCC abordando a importância de se trabalhar com os gêneros do discurso, tanto os de domínio oral quanto os de escrita, as diretrizes curriculares ou os programas de ensino divulgados pelas Secretarias de Educação ainda dão pouca ênfase aos gêneros orais como um objeto de ensino. A convicção de que a escola é o lugar de se ensinar gêneros escritos é um dos possíveis motivos para não se desenvolver atividades planejadas e sistematizadas sobretudo com os variados gêneros orais.

O propósito de trabalhar a oralidade não é com a intenção de ensinar o aluno a falar, uma vez que ele já chega à escola, de certo modo, dominando essa modalidade, mas, conforme postulam Santos, Riche e Teixeira (2015, p.98), “mostrar-lhe como a fala se organiza e ensiná-lo a usar as formas orais em situações que nem sempre ele vivencia no seu cotidiano" a fim de prepará-lo para o exercício da cidadania em circunstâncias distintas ao mesmo tempo em que desenvolve a sua competência comunicativa.

As reflexões de Santos, Riche e Teixeira (2015), a respeito da efetivação de uma prática pedagógica que inclua o ensino dos gêneros orais, salientam a importância do professor conhecer as propostas dos PCN de Língua Portuguesa e o entendimento do porquê de enfatizarem o trabalho com textos em sala de aula. Nessa perspectiva, os gêneros textuais funcionam como um instrumento de ensino, que não só amplia a competência linguística, como propicia formas de aprendizagem e participação social.

Por esse motivo, para o trabalho com a modalidade oral da língua, defende-se o uso dos gêneros orais formais, a exemplo do seminário, como objetos que medeiam a aprendizagem, corroborando, assim, com as postulações dos $\mathrm{PCN}$, segundo os quais

ensinar língua oral deve significar para a escola possibilitar acessos a usos da linguagem mais formalizados e convencionais, que exijam controle mais consciente e voluntário da enuncia- 
Dessa forma, um dos motivos pelos quais a escola deve priorizar o trabalho com os gêneros orais mais formais está relacionado ao fato de os alunos dominarem, com certa desenvoltura, as formas cotidianas de produção oral. Nesse aspecto, o papel da escola é, "então, o de levar os alunos a aprender a moldar as formas cotidianas de produção oral a ouOralidade e tras esferas mais formais de utilização da língua." (GOULART, 2005, p.57). as estratégias

Cabe ressaltar que a 'beleza' das propostas de se trabalhar com os gêneros orais, principalmente com aqueles produzidos na interfade progressão temática ce oral-escrito ou escrito-oral, a exemplo dos seminários, é, diversas vezes, ofuscada por algumas dificuldades imbricadas no processo de ensino. Dentre essas dificuldades, está a de delimitar o oral a fim de escolarizá-lo, porque:

a) ele está presente em todo lugar, tanto fora como dentro da escola; b) é simultaneamente objeto de aprendizagem e ferramenta para o ensino; c) implica o conjunto da pessoa (sua voz, seus gestos, seu olhar, seus movimentos, suas roupas etc.); e d) não combina como modelo de aula tradicional, nas quais só o professor fala e os alunos ficam quietos em seus lugares. (DOLZ; BUENO, 2015, p. 121-2).

Compreende-se que essa dificuldade é decorrente das múltiplas facetas e possibilidades de realização dos textos orais, como sugerem os autores. Uma maneira de resolver esse impasse seria concretizar a escolarização do oral através dos gêneros, como já mencionado, no entanto uma outra dificuldade se apresenta: a disponibilidade de acesso e sistematização didática. Ao contrário dos "gêneros especificamente escritos que podem ser encontrados em vários lugares (livros, jornais, internet etc.), os gêneros orais não se encontram já "recortados" para os professores poderem levá-los para a sala de aula." (DOLZ; BUENO, 2015, p. 122).

Seguindo a perspectiva de que os gêneros orais devem ser ensinados/trabalhados na escola como uma forma de desenvolver a oralidade dos discentes, propõe-se que o gênero seminário, passível de ser utilizado em aulas de diversas disciplinas, seja sistematizado para que 
Evaldo Ribeiro

Andrade

Bárbara

Olímpia

Ramos Melo

404

seja percebido como objeto de ensino ou, como sugerem Gonçalves e Bernardes (2010), como um "objeto de conhecimento" mediado pelo professor no processo de ensino-aprendizagem.

Nesse sentido, o trabalho escolar a partir de um modelo de gênero cujas dimensões ensináveis já tenham sido definidas de maneira precisa, facilita as possibilidades de seu ensino. Esse modelo, segundo Dolz e Gangnon (2015, p. 39), "pode ser também compreendido como uma espécie de matriz permanente que integra os novos textos aos pré-construídos existentes." Em alguns casos, os contornos imprecisos dos gêneros suscitam a criatividade e a autonomia dos alunos.

\section{Seminário: definição e estratégias de progressão temática}

Há situações em que uma pessoa ou um grupo de pessoas, ao desenvolver uma pesquisa sobre um tema especifico e pré-determinado, tendem a apresentar os resultados a um público. Esse tipo de texto, produzido oral e publicamente, chamado seminário, é um gênero expositivo cuja finalidade é a transmissão de saberes construídos historicamente pela humanidade. Por ser um gênero oral, o seminário só se realiza plenamente quando é apresentado numa situação concreta de interação.

Muito mais do que uma técnica de estudo, o seminário, de acordo com Dolz et al (2004), representa um instrumento de transmissão de diversos conteúdos, principalmente para aqueles que o prepara e apresenta, pois "fornece um instrumento para aprender conteúdos diversificados, mas estruturados graças ao enquadramento viabilizado pelo gênero textual." (DOLZ et al, 2004, p. 184). Os autores também definem seminário "como um gênero textual público, relativamente formal e específico, no qual um expositor especialista dirige-se a um auditório, de maneira (explicitamente) estruturada, para lhe transmitir informações, descrever-lhe ou lhe explicar alguma coisa." (DOLZ et al, 2004, p. 185). Desse modo, segundo os articulistas teóricos, esse gênero apresenta a particularidade de uma comunicação bipolar, porque nela, numa situação de comunicação específica, se apresentam o expositor ou "especialista" e o destinatário ou auditório.

Baseando-se nos autores supracitados, Bueno e Abreu (2010, p. 123) descrevem o seminário como "um gênero oral bastante complexo na medida em que demanda, para ser bem realizado, capacidade supe- 
rior à necessária para se fazer uma exposição oral em público." Os autores também falam da necessidade de dividir o seminário em duas etapas sendo a primeira a preparação e a segunda a apresentação.

A primeira etapa, segundo Bueno e Abreu (2010, p. 123), “diz respeito à organização do grupo, do tempo e distribuição das tarefas, pesquisa e leitura de textos, fichamentos," elaboração de roteiros, slides, transparências etc. A segunda etapa refere-se à efetivação do seminário propriamente dito, em que o locutor deverá saber usar a linguagem adequada, atentar para o conteúdo a ser exposto e a ordem de apresentação, "será preciso ter claro qual a aparência e postura física a ser adotada (roupas, mãos, olhares, tom da voz etc.) para que se consiga atingir a finalidade do seminário." (BUENO E ABREU, 2010, p. 123). Na concepção desses estudiosos, a realização do seminário na perspectiva

Oralidade e as estratégias de progressão temática do ensino, em que se trata de construir um objeto ensinável, requer um elevado nível de elaboração e planejamento, não devendo ocorrer de forma improvisada.

Fávero, Andrade e Aquino (2012), ao elencarem os aspectos significativos que devem ser levados em conta na produção de um texto oral, caracterizam o seminário, no contexto de sala de aula, da seguinte forma: faz parte de uma situação discursiva formal; o evento de fala é institucional; tema e objetivos são estabelecidos previamente; o grau de preparo necessário para a efetivação do evento é elevado; a relação entre os participantes é de amizade ou de conhecidos e o canal utilizado para a realização do evento é a interação face a face.

Sabe-se que o gênero seminário é caracterizado principalmente pela atividade de expor. Essa atividade é definida, conforme Gomes-Santos (2012, p. 16), como "um movimento de retorno a um repertório de conhecimentos associados à finalidade de apresentá-la a alguém." Nesse sentido, ganha destaque, nesse processo de construção do gênero, o expositor, pois é ele quem fundamentalmente coloca em diálogo uma multiplicidade de textos para ser apresentada ao público para o qual se destina a exposição.

Para que todo esse processo se configure realmente no gênero seminário, essa atividade requer um planejamento em que o aluno ou o grupo seleciona as informações, a partir de pesquisas em variadas fontes, organiza-as em um novo texto e elabora o conteúdo (roteiro) a ser exposto. Esse momento de preparação do seminário é tão importante quanto a apresentação em si, por isso deve ser bem elaborado. 
Todas as etapas de desenvolvimento do seminário elencadas não são estanques e nem descontínuas, como bem aponta Gomes-santos (2012), principalmente quando se trata da exposição propriamente dita, uma vez que este momento é

Evaldo Ribeiro

Andrade

Bárbara

Olímpia

Ramos Melo

altamente sensível à aprendizagem e ao desenvolvimento do aluno, já que lhe coloca na situação tensa de transformar o roteiro elaborado em um objeto compartilhado, o que implica acionar um conjunto de estratégias que dão corpo à exposição, que constroem sua textualidade (GOMES-SANTOS, 2012, p. 99).

As palavras do articulista teórico evidenciam o quão deve ser bem trabalhada a etapa do planejamento do seminário para que no momento da exposição (situação colocada como tensa), o aluno-expositor possa satisfatoriamente executar a apresentação. $O$ autor fala também das estratégias de formulação textual acionadas pelos alunos durante a exposição.

\subsection{Estratégias de progressão temática}

Em um seminário, a progressão do tema pode ser efetivada pelo uso de diferentes estratégias que, por um lado, ajudam, conforme Gomes-Santos (2012), na contextualização do tema, chamando a atenção do auditório para ele, e por outro, a topicalizá-lo, ou seja, auxiliam no fracionamento das informações a serem expostas. Para o teórico, as principais estratégias de progressão do seminário são a exemplificação, a reformulação, a narrativização e o comentário, sendo assim caracterizadas:

Exemplificação - estratégia que, na exposição, permite especificar os conteúdos topicalizados e assumir uma função ilustrativa como também explicativa desses conteúdos. Por atuar sobre uma porção específica do conjunto de informações que os alunos expõem, algumas formas linguísticas podem indicar essa estratégia, tais como vou citar, por exemplo, tipo, é o caso de etc.

Reformulação - essa estratégia incide sobre porções textuais e procura reorganizá-las em diferentes extensões e com graus diversos de transformação. De acordo com Gomes-Santos (2012), a reformulação tem uma função didática, porque busca tornar mais explícito para o interlocutor o conteúdo topicalizado. Marcas linguísticas como quer dizer, ou seja, sinalizam a estratégia de reformulação. Em alguns casos, 
essa estratégia pode ser introduzida não por uma marca linguística particular, mas pela entonação ou a ênfase dada a determinado segmento quando recategorizado.

Narrativização - segundo Gomes-Santos (2012), essa estratégia, de forma indireta, permite o desenvolvimento do roteiro temático da exposição, podendo ser mediada pelo relato de fatos reais ou imaginários. Ela tem como domínio de atuação tanto na contextualização do tema do seminário quanto na topicalização dos conteúdos do roteiro. Enquanto as estratégias de exemplificação e reformulação deixam mais evidentes os conteúdos expostos, a narrativização camufla-os nos eventos e nas ações que o expositor relata. Certa vez eu vi, teve (houve) uma vez que são algumas das marcas linguísticas que podem introduzir os relatos feitos. Essa estratégia é mais comum quando os alunos estão no início dos anos escolares.

Oralidade e as estratégias de progressão temática

Comentário - através dessa estratégia, o expositor posiciona-se em relação ao conteúdo exposto. Para Gomes-Santos (2012), provavelmente esta seja a estratégia que, em maior grau, permita ao expositor distanciar-se do roteiro temático da exposição, uma vez que seu objetivo não é topicalizar seus diferentes conteúdos, mas submeter uma determinada verdade sobre eles à apreciação do auditório. "É a estratégia mais sensível à individualidade do expositor", pois representa o momento "em que ele complementa à sua maneira os conteúdos expostos, conforme seu repertório pessoal de conhecimento" (GOMES-SANTOS, 2012, p. 110).

De acordo com o autor, o uso dessas estratégias pelo expositor tem, por finalidade, tentar constantemente fazer o auditório compreender os conteúdos, interessar-se por eles como maneira de adesão à apresentação. Ainda sobre essas estratégias, Gomes-Santos (2012) apresenta as quatro que ele identificou em suas pesquisas com alunos do ensino fundamental. No entanto, dependendo da turma, do nível de escolaridade e de criatividade e de preparo dos alunos, é possível aparecerem outras táticas que auxiliem na progressão do tema. Fica, assim, a expectativa deste estudo identificar outra estratégia que não foi elencada pelo estudioso.

\section{Metodologia}

Quanto aos seus objetivos, esta pesquisa caracteriza-se como exploratória, uma vez que seu "objetivo é proporcionar maior familiaridade com o problema, com vistas a torná-lo mais explícito ou a constituir hipóteses." (GIL, 2002, p. 41). Assim, ao investigar o ensino do gênero seminário como 
Evaldo Ribeiro

Andrade

Bárbara

Olímpia

Ramos Melo

408 prática de oralidade na escola, possibilitou-se explicitar os possíveis problemas detectados. Também é plausível classificar esta pesquisa como descritiva, pois apresenta como particularidade, conforme Gil (2002, p. 42), "a descrição das características de determinada população ou fenômeno", visto que foi necessário descrever como ocorreram determinados eventos relacionados às estratégias de progressão temática na exposição do gênero seminário. No tocante ao tratamento dos dados, classifica-se como qualitativa, haja vista que seu foco é a compreensão e a interpretação de determinados comportamentos da situação em estudo.

A pesquisa realizada ocorreu em uma turma de $9^{\circ}$ ano, turno manhã, de uma escola pública municipal de Teresina-PI. Nesta turma estudavam 40 alunos com idade entre 14 e 16 anos, sendo em sua maioria estudantes do sexo feminino. Por envolver seres humanos, este estudo foi submetido ao Comitê de Ética em Pesquisa (CEP) e aprovado pelo mesmo através do Certificado de Apresentação para Apreciação Ética - CAAE 63925416.0.0000.5209, cujo parecer está inscrito sob o número 1.900.503.

Para a coleta de dados, utilizou-se a proposta metodológica de uma atividade diagnóstica. Para isso, inicialmente houve uma conversa com os alunos sobre a proposta de um trabalho em que eles deveriam desenvolvê-lo e apresentá-lo através de uma apresentação oral, isto é, por meio do gênero seminário.

A fim de evitar possíveis constrangimentos, os alunos foram informados que as apresentações seriam gravadas por meio de um gravador de áudio e que os seus nomes seriam mantidos em sigilo, sendo que a identificação de cada aluno foi feita pelas abreviações EXP 1, EXP 2, EXP 3... Em seguida, a turma foi dividida em seis grupos e a formação ocorreu a partir da afinidade entre os componentes, resultando na seguinte configuração: um grupo com oito membros, dois com sete e três com seis. Depois houve o sorteio dos temas e da ordem de apresentação para cada grupo. A escolha dos temas segue as orientações dos PCN no que diz respeito aos temas transversais. Optou-se pelas seguintes temáticas, já na ordem de apresentação dos grupos: $G 1$ - Combate à dengue; G2 - Discriminação e preconceito racial; G3 - O uso racional da água; G4 - A violência contra a mulher; $G 5$ - Os usos inadequados da internet e das redes sociais e G6 - A preservação ambiental.

A seleção dessas temáticas justifica-se porque elas expressam conceitos e valores básicos à cidadania e à democracia e por obedecerem a questões urgentes e importantes para a sociedade hodierna. Des- 
tarte, são temas vivenciados intensamente pelas comunidades, pelas famílias, pelos educadores e pelos alunos em seu dia-a-dia.

Após o sorteio, foram dadas as orientações gerais sobre o gênero seminário tais como: informações a respeito do tempo de apresentação, postura do expositor, elaboração de material, indicação de fontes e linguagem a ser utilizada.

Estipulou-se um prazo de quinze dias para que os alunos pesquisassem e organizassem a apresentação que deveria durar até vinte

Oralidade e as estratégias de progressão temática

\section{Análise e discussão dos dados}

A realização de um seminário é o momento em que os expositores tornam público a uma plateia um roteiro temático previamente elaborado. Surge, nesse momento, a capacidade do(s) expositor(es) de dar(em) voz ao roteiro elaborado, para isso, segundo Dolz et al (2004), citando Goffman (1987), há três maneiras de "dar vida às palavras pronunciadas" (DOLZ et al, 2004, p. 190): leitura, memorização e fala espontânea. Dessa forma, durante a apresentação, o expositor pode utilizar individualmente uma dessas maneiras ou combiná-las.

Além disso, durante a apresentação do seminário, gênero de natureza coconstruída, os expositores precisam transformar o roteiro elaborado em um objeto compartilhado e isso implica dizer que eles deverão acionar um conjunto de estratégias que irão, segundo Gomes-Santos (2012), dar corpo à exposição, construir a textualidade desse gênero. Entre essas estratégias de formulação textual que permitem a progressão do tema do seminário estão a exemplificação, a reformulação, a narrativização e o comentário. $O$ autor cita essas quatro como as mais elementares, mas por ser um gênero muito dinâmico quanto a sua forma de realização, 
Evaldo Ribeiro

outras estratégias podem ser efetivadas em sua composição. Passa-se a analisar, a seguir, a presença dessas estratégias nos seminários apresentados. Vale ressaltar que nem todos os grupos, em suas apresentações, utilizaram todas essas estratégias e que outra maneira de progressão temática foi identificada, a exemplo dos questionamentos.

\section{Andrade \\ 4.1. Exemplificação \\ A finalidade da exemplificação é especificar, através de exemplos, os Bárbara conteúdos topicalizados. Na exposição sobre o combate à dengue (G1), Olímpia o recurso da exemplificação, além de ter uma função ilustrativa na elo- Ramos Melo cução, também é explicativa, quando o expositor tenta explicar os tipos de plantas que podem ser feitos chás para tratar a dengue clássica. 0 re- curso linguístico utilizado para indicar essa estratégia foi o por exemplo.}

EXP 5: [...] é possível também tratar a dengue clássica da forma mais natural através de plantas, ou seja através de chás feito de plantas, por exemplo, com a, planta a flor/ a flor (ícone) e a malva branca são exemplos dessas plantas que podem aliviar a febre ajudar na:: na, ajudar o organismo a combater o vírus mais facilmente $[. .$.

A exemplificação assume a mesma função ilustrativa na elocução do EXP 6 do G2 que, ao falar sobre atitudes racistas, faz uso dessa estratégia através de uma pergunta hipotética. A intenção não é apenas perguntar, mas, através desse questionamento, mostrar um exemplo de uma atitude racista. $O$ aluno cria uma situação hipotética, coloca-se como arquétipo de racista e usa como vítima de racismo uma colega negra. A expressão linguística que dá origem essa estratégia é a oração se eu fosse.

EXP 6: [...] se eu fosse o dono de uma empresa e a Alessandra quisesse trabalhar na minha empresa, e eu fosse racista, vocês acham que eu deixaria ela, trabalhar na minha empresa?...

Já na exposição a seguir, ainda do mesmo grupo (G2), mas tratando agora sobre como agir nos casos de discriminação, a estratégia da exemplificação, na fala do EXP 8, tem função de enumerar os detalhes dos casos de discriminação. Isso é feito pelo uso do termo tipo. 
EXP 8: [...] se você quer denunciar eu acho tão importante que você preserve todos os detalhes do caso, tipo horário, data local e situação e também é importante que você apresente testemunhas que comprovem a ocorrência do crime...

A exemplificação foi a estratégia mais recorrente pelos alunos na exposição dos seminários, principalmente quando desempenha função explicativa marcada pelo operador linguístico por exemplo. Ela esteve presente em todos os grupos, todavia não se transcreveu todos os exemplos encontrados para a análise não ficar redundante.

Os exemplos extraídos dos seminários confirmam as postulações de Gomes-Santos (2012) ao assegurar que a exemplificação age sobre uma parte específica do conjunto de informações e pode ser exposta

Oralidade e as estratégias de progressão temática por diferentes marcas linguísticas. A subseção seguinte trata sobre a estratégia de reformulação.

\subsection{Reformulação}

A estratégia de reformulação consiste, segundo Gomes-Santos (2012), em tornar mais explícito para o interlocutor as informações dos tópicos. Isso implica dizer que o conteúdo topicalizado passará por um processo de transformação para facilitar sua compreensão pelo interlocutor.

Nas exposições analisadas, apenas três grupos (G1, G2 e G4) apresentaram em sua progressão textual a estratégia de reformulação. Para esta análise, apresenta-se um exemplo para cada grupo. Na exposição do G1, o EXP 5, ao falar sobre o tratamento da dengue, reelabora a frase oral incidindo a reformulação sobre uma porção específica da oração anterior ao marcador ou seja, no caso, o vocábulo plantas. Assim, o expositor esclarece que o tratamento natural da dengue clássica não é através de plantas, mas de chás feitos de plantas.

EXP 5: [...] é possível também tratar a dengue clássica da forma mais natural através de plantas, ou seja através de chás feito de plantas [...]

O mesmo reformulador também é usado pelo EXP 2 do segundo grupo para explicar o significado do termo inafiançáveis. Além do ou seja, há também o uso da expressão o que significa dizer para explicar o significado do vocábulo imprescritíveis. Novamente observa-se o que 


\section{Evaldo Ribeiro}

Andrade

Bárbara

Olímpia

Ramos Melo

Gomes-Santos (2012) considera como a função didática da reformulação, pois a intenção do locutor, consciente ou inconscientemente, ao reformular, é garantir que a plateia compreenda o que foi exposto.

EXP 2: [...] a discriminação e o preconceito racial embora sejam considerados crimes ainda são práticas recorrentes na sociedade brasileira, é importante saber que estes são crimes inafiançáveis, ou seja não pode haver liberdade provisória mediante pagamento de fiança é imprescritíveis... dizer/o que significa dizer que a denúncia pode ocorrer a qualquer momento independentemente do tempo que se tenha passado desde $o$ ato descriminatório e criminoso

No G4, o EXP 1 reformula uma porção de texto, relativa às consequências da violência psicológica, lida por ele mesmo. Essa estratégia de reformular um texto lido é muito comum quando o aluno apresenta o seminário alternando leitura do texto com a fala espontânea. É uma estratégia que dá ao expositor uma maior segurança em relação ao não esquecimento das informações a serem apresentadas. No exemplo a seguir, ao tentar reformular um fragmento textual lido, o expositor acrescenta uma informação que só se relaciona com o número de afetados pela violência psicológica, não abordando as consequências dessa violência.

EXP 1: [...] "noventa e quatro por cento sofreram," é:: inclusive, inclusivamente "esse tipo de violência que abarca de acordo com os pesquisadores, assédio moral por parte do: cuidador im-posição de medo extremo e controle e: coercitivo insultos graves, humilhações ameaças Exigências EXtremas, REjeição e isolamentos" [...] gente isso é muito grave, “a psicológica foi a MAIs fortemente associada com transtorno DEpressivo, distúrbio de ansiedade social e GEneralizada, dificuldade de formar vínculos afetivos e abusos, de substâncias" ou seja, dentre todas as violências, a psicológica é a que mais abrange a população

A reformulação, portanto, se for bem elaborada ajuda, no processo de exposição, a esclarecer o conteúdo exposto e a facilitar para o interlocutor o processo de compreensão textual. Outra estratégia que possibilita a progressão de um seminário é a narrativização, que será abordada na subseção seguinte. 


\subsection{Narrativização}

Quando o expositor, para contextualizar melhor o tema de sua apresentação, relata fatos reais ou fictícios, ele está utilizando a estratégia de progressão temática da narrativização. Para Gomes-Santos (2012), os conteúdos expostos na exposição, nessa estratégia, ficam camuflados nos eventos e nas ações relatadas pelo expositor.

Dos seis grupos analisados, apenas um (G4) utilizou a estratégia de narrativização em sua composição. $\mathrm{Na}$ exposição sobre a violência contra a mulher, o EXP 3 contextualiza sua fala fazendo um breve relato sobre a origem da lei Maria da Penha. As marcas linguísticas que evidenciam essa estratégia estão relacionadas aos eventos e às ações no pretérito perfeito. Além disso, as locuções adverbiais temporais (depois de, depois desses) reforçam a ideia de narratividade do texto.

Oralidade e as estratégias de progressão temática

EXP 3: boa tarde, vou falar sobre a lei Maria da Penha, a lei Maria da Penha foi decretado pelo Congresso Nacional e pelo ex-presidente Luís Inácio Lula da Silva no dia:: sete de agosto de dois mil e seis e no/perante ao caso doze mil cinquenta e um de Maria:: da Penha Ferraz, ela sofreu agressão é:, vamos dizer violência durante os vinte e três anos de seu casamento, em mil novecentos e oitenta e três ela, teve, duas tentativas de homicídios, pelo marido, e depois de dezenove anos ele passou dezenove anos sem julgamento, depois desses dezenove anos ele passou dois anos em regime fechado,

Além da narrativização, outra estratégia de progressão temática usada no desenvolvimento de um seminário foi o comentário. Esse será o assunto da subseção seguinte.

\subsection{Comentário}

Como estratégia que promove a progressão de uma exposição ou seminário, o comentário é a que possibilita, de acordo com Gomes-Santos (2012), um posicionamento do expositor com relação ao conteúdo apresentado. E dependendo do repertório pessoal de conhecimentos do sujeito que expõe, essa estratégia tende a facilitar o seu trabalho como também conquistar a adesão do auditório.

Após analisar as apresentações dos seis grupos, verificou-se que, em quatro deles, alguns expositores fizeram uso dessa estratégia. Primeiramente, observou-se que no G2, o comentário foi exposto somente 
na parte final da exposição quando o EXP 1 diz novamente a finalidade do trabalho do grupo. Ao dizê-la, o expositor reafirma suas intenções e passa também a agir sobre o auditório, uma vez que o comentário feito tem um forte valor apelativo.

Evaldo Ribeiro

Andrade

Bárbara

Olímpia

Ramos Melo

EXP 1: então, nosso grupo teve como finalidade mostrar pra vocês que "se nós combatermos o preconceito, racismo e discriminação estaremos dando um grande passo para a melhoria do mundo, de nós mesmos e dos demais que são apenas nossa imagem e semelhança"

$\mathrm{Na}$ exposição sobre violência contra a mulher (G4), o EXP 3 comenta a respeito das leis e do papel dos cidadãos. Esse comentário evidencia a opinião do expositor a respeito da forma de agir das pessoas diante do contexto de violência como também apresenta um caráter injuntivo, assumindo um tom de inconformismo com as atitudes das pessoas, de modo geral, e principalmente com a justiça brasileira.

EXP 3: o grande mal das pessoas daqui é isso eles pensam que as leis, só são mais leis, do tipo tá aqui no papel e não vai passar disso, a gente não deve pensar assim, (tem) que exercer nosso papel como cidadão, sim nós vivemos num mun/num país impune, o Brasil é um país altamente impune, impune PORque aqui menor de dezoito anos ele é, vamos dizer, protegido pela:: justiça,

Outro caso de uso da estratégia de comentário ocorre quando o EXP 1, na exposição que aborda o tema sobre os usos inadequados da internet (G5), alerta para os cuidados que se dever ter ao usar as redes sociais. As orientações expostas possuem um teor persuasivo, revelando, dessa forma, que essa estratégia possui como característica um caráter altamente argumentativo, conforme cita Gomes-Santos (2012).

EXP 1: então, hoje em dia a gente deve ter muito cuidado nas redes sociais na internet, por exemplo WhatsApp, ter muito cuidado com quem você conversa, com quem você tá teclando, porque as vezes as pessoas, que nem no caso tava explicando lá fora, pede foto nua sua e você vai posta e lá/causa violência [...] 
Por último, no fechamento da exposição sobre preservação ambiental (G6), o EXP 1 encerra sua fala proferindo o comentário na forma de um conselho a respeito do que todos devem fazer para continuar preservando o meio ambiente. Essa estratégia possui um caráter interativo-persuasivo, pois tem como direcionamento a plateia e dela se espera uma mudança de atitude em relação às formas de preservar o meio ambiente.

Oralidade e as estratégias de progressão temática sas exemplificações, destaca-se pelo seu forte valor argumentativo, uma vez que o expositor direciona o fluxo informacional a seus interlocutores para que estes aceitem suas ideias compartilhando da mesma opinião e/ou mude de atitude.

É importante destacar que além dessas quatro estratégias, identificou-se também uma outra que possibilita a progressão textual e que não foi proposta por Gomes-Santos (2012). Essa distinta maneira de progredir o tópico é pautada na elaboração de perguntas pelo expositor durante a sua exposição, por isso, denominou-se aqui de questionamentos. Embora não estivesse prevista para ser uma das categorias de análise, optou-se por analisá-la também, dessa forma, a subseção seguinte é destinada para a abordagem analítica dessa estratégia.

\subsection{Questionamentos}

Ao longo das apresentações dos seminários, verificou-se que alguns expositores, para dar continuidade às suas falas, recorriam às autoindagações. Essa estratégia funciona como uma espécie de roteiro das apresentações. As perguntas são feitas para serem respondidas pelos próprios expositores ao longo das suas exposições. Tal estratégia pode funcionar ainda como uma forma de contextualização do tópico.

$\mathrm{Na}$ exposição do G2, o EXP 1, ao contextualizar o tema discriminação e preconceito racial com a leitura de um versículo da Bíblia, começa a fazer uma série de questionamentos que possibilitaram a fruição de sua exposição. Esses questionamentos não eram apenas perguntas retóricas, mas perguntas que permitiam que a plateia refletisse acerca 


\section{Evaldo Ribeiro}

Andrade

Bárbara

Olímpia

Ramos Melo

da temática abordada. Apesar do uso do MD interacional de natureza fática, né isso?, o expositor dá sequência a sua apresentação realizando indagações mais elaboradas.

EXP 1: [...] tem muitas pessoas que se acham melhor do que outras, e daí vem aquela pergunta, por que que tem pessoas que se acham melhor do que eu ou de qualquer um, de nós aqui se nós somos fei/é/é criaturas feitas por Deus?... na Bíblia mesmo fala que nós somos imagem e semelhança dele... [...] ele não escolhe que ele vai usar, né isso? não importa se ele é moreno ou branco tem cabelos lisos ou cacheados, não importa, tipo se Deus não nos julga pelas nossas características por que, que nós vamos fazer tal acepção? [...]

Assumindo um caráter provocativo e surpreendente ao colocar o esgoto como solução para a crise hídrica, o EXP 1 do G3 também faz uso de questionamentos para situar a sua exposição e assim ter a atenção da plateia.

EXP 1: o uso racional da água, cada vez mais possível, e se a solução para a crise hid/ hídrica do Brasil estivesse no esgoto? estudiosos afirmam que a água do reuso pode ser a nossa única alternativa para a questão do abastecimento [...] "a água de reuso deve seguir parâmetros de qualidade de acordo com as formas de se utilizá-la, mas afinal como funciona o processo de tratamento de esgoto?"

No G4, mais de um expositor utilizou essa estratégia em sua fala. Optou-se por mostrar o caso do EXP 2 porque ele, didaticamente, organizou toda a sua apresentação através de questionamentos. Anotou em um cartaz somente as perguntas, leu e as respondeu de forma mecânica, pouco interativa, por vezes monótona. Ao utilizar a estratégia dessa maneira, o expositor deixou em evidência que havia memorizado as respostas, pois sua apresentação não foi além do que estava previsto no par pergunta-resposta.

EXP 2: ((olha as anotações do cartaz)) “o que é assédio sexual?", assédio sexual (indica) qualquer comportamento sexual indesejado, pode-se manifestar de forma grosseira, pode também causar constrangimento à vítima... "o que fazer se estou sofrendo assédio sexual?" 
você não pode transmitir insegurança, não ria de piadas picantes, [...] você deve ligar cento e oitenta, [...] "de que forma o assédio sexual pode se manifestar?", pode se manifestar de duas formas, física e verbal, verbal é quando você constrange um pessoa com uma cantada, indecente é claro, e fí:sica é quando você toca em partes, partes da mulher quando ela não te dá permissão para isso... "quais os lugares onde mais ocorre esse ato?", geralmente é nos ônibus, nas escolas, nos hospitais e lugares públicos

Oralidade e as estratégias

Nesse sentido, compreende-se que os questionamentos, assim como a exemplificação, a reformulação, a narrativização e o comentário, são importantes estratégias para a progressão do tema de uma exposição e para o ensino da oralidade. 0 quadro a seguir apresenta uma de progressão temática síntese da ocorrência dessas estratégias em cada grupo.

Quadro 1: Síntese das estratégias de progressão temática nos grupos

\begin{tabular}{|l|c|c|c|c|c|c|}
\hline \multirow{2}{*}{ Estratégias } & \multicolumn{7}{|c|}{ Grupos } \\
\cline { 2 - 7 } & G1 & G2 & G3 & G4 & G5 & G6 \\
\hline Exemplificação & $\mathrm{X}$ & $\mathrm{X}$ & $\mathrm{X}$ & $\mathrm{X}$ & $\mathrm{X}$ & $\mathrm{X}$ \\
\hline Reformulação & $\mathrm{X}$ & $\mathrm{X}$ & & $\mathrm{X}$ & & \\
\hline Narrativização & & & & $\mathrm{X}$ & & \\
\hline Comentário & & $\mathrm{X}$ & & $\mathrm{X}$ & $\mathrm{X}$ & $\mathrm{X}$ \\
\hline Questionamentos & & $\mathrm{X}$ & $\mathrm{X}$ & $\mathrm{X}$ & & \\
\hline
\end{tabular}

FONTE: Elaborado pelos autores.

Esse quadro traz um panorama sintético das estratégias de progressão temática identificadas nas exposições dos grupos. Chama a atenção alguns fatos, dentre os quais: a) algumas estratégias foram mais utilizadas que outras, como a exemplificação e o comentário; b) houve estratégia pouco utilizada, a exemplo da narrativização, usada por um único grupo; d) um único grupo (G4) operacionalizou todas as estratégias tratadas nesta pesquisa; d) quatro grupos (a maioria) em suas apresentações usaram apenas duas estratégias. Diante disso, é necessário salientar que todas as estratégias são importantes na progressão temática de uma exposição e que elas podem ser usadas de forma complementar. 
Evaldo Ribeiro

Andrade

Bárbara

Olímpia

Ramos Melo

\section{Considerações finais}

As análises demostram que alguns grupos conseguiram operacionalizar mais estratégias de progressão que outros. De certa forma, quanto mais estratégias forem utilizadas de forma adequada, mais proveitosa será a apresentação do seminário. Essas táticas que conduzem à progressão do tema de uma exposição fundamentam-se, segundo Gomes-Santos (2012, p. 111), "na tentativa constante do expositor em fazer o auditório compreender os conteúdos, interessar-se por eles e, desse modo, aderir à exposição." As palavras do autor confirmam o que foi constatado nessa pesquisa. Os dois grupos (G2 e G4), por apresentarem um maior número de estratégias distintas, quatro e cinco, respectivamente, foram os que conseguiram um melhor desempenho nas exposições, tanto em relação à adesão da plateia, uma vez que parecia compreender o conteúdo, como em relação ao grau de informatividade elencado pelos apresentadores que demonstraram desenvoltura e domínio de conteúdo. E, por causa disso, também foram os que melhor se sobressaíram.

Os demais grupos, apenas com duas estratégias, não conseguiram manter por muito tempo a plateia atenta ao que era exposto. Essa constatação revela que faltou planejamento dos grupos quanto à forma de apresentar o seminário, ratificando a ideia de que esse gênero não deve ocorrer na forma de improvisação. Caso isso ocorra, o resultado é frustrante, porque o público perde o interesse, e pouco produtivo, pois, nem quem apresenta e nem quem está como expectador alcança a aprendizagem esperada já que não ocorrem de forma efetiva as relações interacionais previstas para o gênero seminário. Portanto, o sucesso de uma exposição depende, dentre outros fatores, do uso de estratégias de progressão temáticas interessantes e eficientes que despertem o interesse da plateia em ouvir e em interagir com o que está sendo exposto. 


\section{REFERÊNCIAS}

BRASIL. Ministério da Educação. Secretaria da Educação Básica. Base nacional comum curricular. Brasília, DF, 2017. Disponível em: $<$ http://basenacionalcomum.mec.gov.br/images/BNCC_EI_EF_110518_versaofinal_site.pdf> Acesso em: dez. 2018.

BRASIL, Ministério da Educação, Secretaria de Educação Básica. ParâOralidade e metros Curriculares Nacionais. Terceiro e quarto ciclos do ensino as estratégias fundamental. Língua Portuguesa. Brasília: Ministério da Educação, 1998. de progressão temática

BUENO, Luzia; ABREU, Cláudia de Jesus. Gêneros orais na universidade: relato de uma experiência com o seminário. Synergies 419 Brésil n 8, 2010. p. 119-125.

COSTA-HÜBES, Terezinha da C. SWIDERSKI, Rosiane M. S. Gêneros orais e ensino: uma experiência didática com notícia televisiva. In: BUENO, Luzia. COSTA-HÜBES, Terezinha da C. (Orgs.). Gêneros orais no ensino. Campinas-SP: Mercado de Letras, 2015. p. 139-168.

DOLZ, Joaquim. BUENO, Luzia. Gêneros orais e gêneros produzidos na interface escrito-oral: o discurso de formatura no ensino fundamental e sua contribuição para o letramento escolar. In: BUENO, Luzia. COSTA-HÜBES, Terezinha da C. (Orgs.). Gêneros orais no ensino. Campinas-SP: Mercado de Letras, 2015. p. 117-138.

DOLZ, Joaquim. GAGNON, Roxane. O gênero de texto, uma ferramenta didática para desenvolver a linguagem oral e escrita. In: BUENO, Luzia. COSTA-HÜBES, Terezinha da C. (Orgs.). Gêneros orais no ensino. Campinas-SP: Mercado de Letras, 2015. p. 23-56.

DOLZ, Joaquim et al. A exposição oral. In: - Gêneros orais e escritos na escola. Tradução e organização Roxane Rojo e Glaís Sales Cordeiro. Campinas/SP: Mercado de Letras, 2004. p. 183-211.

FÁVERO, Leonor L.; ANDRADE, Maria Lúcia C. V. O.; AQUINO, Zilda G. O. Oralidade e escrita: perspectivas para o ensino de língua materna. 8 ed. São Paulo: Cortez, 2012. 
GIL, Antônio Carlos. Como elaborar projetos de pesquisa. 4 ed. São Paulo: Atlas, 2002.

GOMES-SANTOS, Sandoval Nonato. A exposição oral: nos anos iniciais do ensino fundamental. São Paulo: Cortez, 2012.

Evaldo Ribeiro

Andrade GONÇALVES, A. V.; BERNARDES, E. S. O gênero seminário: usos e dimensões ensináveis. Revista Linguasagem, ISSN: 1983-6988, São

Bárbara Carlos, 2010.

Olímpia

Ramos Melo

GOULART, C. As práticas orais na escola: o seminário como objeto de ensino. Dissertação (Mestrado em Linguística Aplicada) - Insti420 tuto de Estudos da Linguagem, Universidade Estadual de Campinas, Campinas, 2005. $210 \mathrm{f}$.

KOCH, Ingedore G. V. Especificidade do texto falado. In: JUBRAN, Clélia Spinardi (org.). A construção do texto falado. São Paulo: Contexto, 2015. p. 39-46.

SANTOS, Leonor W. RICHE, Rosa C. TEIXEIRA, Claudia S. Análise e produção de textos. São Paulo: Contexto, 2015. 